\title{
DETERIORATION AFTER MITRAL VALVOTOMY
}

\author{
BY \\ CHARLES BAKER AND W. E. HANCOCK* \\ From the Cardiac Department, Guy's Hospital \\ Received August 24, 1959
}

It is now more than ten years since the introduction of mitral valvotomy. The initial results (Baker, Brock, and Campbell 1950; Baker et al., 1952) and a three-year follow-up of the first 45 Guy's cases (Baker et al., 1955) have been published. We now report a larger group of 200 patients followed up for over five years, which allows a more complete assessment of the long-term benefits of mitral valvotomy and of the incidence of restenosis and other causes of deterioration.

The details and length of the follow-up were as follows. In a consecutive series of patients referred to Guy's Hospital there were 239 operations between September 16, 1948 and November 6, 1953. Of these 239 patients 12 were excluded, 7 because their operation was for dominant mitral regurgitation, 2 because the stenosis at operation was insignificant, and 3 because follow-up was not possible. There were, in addition, 27 operative deaths, a mortality of 11.3 per cent. These 39 patients are not further considered, leaving 200 patients followed up for over 5 years after valvotomy, 98 for over 6 years, 36 for 7 years, and 8 for 8 years or more.

Clinical assessment has been made at yearly intervals using the grades of disability previously defined (Baker et al., 1952), which are briefly: 0, no disability; 1, slight disability; 2, moderate disability; 3, severe disability; and 4, total incapacity. Improvement of 3 or more grades is considered an excellent result, of two grades a good result, of one grade a fair result, and no grade of improvement a poor result.

For simplicity in reviewing these patients, the good and excellent results have been classed together as "good", and the poor and fair results have been classed together as "poor". Those who deteriorated after having good results for one year or longer are classed as "deteriorated." In discussing the causes of deterioration they are compared with the good results who have maintained their improvement to date.

\section{RESULTS OF VALVOTOMY}

The results of operation, assessed at one year and at the latest follow-up, five or more years after operation, are shown in Table I. At the earlier assessment 170 patients had good or excellent results, or 85 per cent of those surviving operation, the same proportion as in the first 45 cases previously reported. At the latest follow-up, 51 (or 30 per cent) of the 170 good and excellent results have deteriorated and 12 have died. There were 30 patients with a fair or poor initial result; 25 of those seen have deteriorated and 16 have died. Thus, after a follow-up period ranging from 5 to 10 years, 119 or 59.5 per cent still maintain good or excellent results; 81 or 40.5 per cent are not significantly better than before operation, and 28 of these have died.

Poor Results after Operation. The following factors were responsible for the poor results initially in 30 patients. In 27 the valvotomy was unsatisfactory, because the stenosis was not adequately relieved (11 cases), was only partially relieved with the addition of regurgitation (12 cases), or because free regurgitation resulted ( 4 cases). Three others had a satisfactory valvotomy but two

* Research Fellow of the American Heart Association and Research Fellow, Cardiac Department, Guy's Hospital. 
TABLE I

Results in Total Follow-UP Period

\begin{tabular}{|c|c|c|c|}
\hline \multirow{2}{*}{\multicolumn{2}{|c|}{$\begin{array}{c}\text { Clinical assessment at end of one } \\
\text { year }\end{array}$}} & \multicolumn{2}{|c|}{ Subsequent follow-up } \\
\hline & & Deteriorated & Remain the \\
\hline Poor: poor and fair results & 30 & $25(16)^{*}$ & 5 \\
\hline $\begin{array}{l}\text { Good: good and excellent } \\
\text { results .. } \quad . .\end{array}$ & 170 & $51(12)^{*}$ & 119 \\
\hline Total & 200 & $76(28)^{*}$ & 124 \\
\hline
\end{tabular}

* The numbers in brackets show the number who have died.

were disabled from the effects of embolism at operation and one from damage to the ventricle that caused a cardiac aneurysm in a woman who already had some systemic hypertension. One patient committed suicide three months after operation, and although his valvotomy was not complete he might have been a good result for a limited period. Calcification of the valve was present in 14 of these 30 patients and undoubtedly contributed to the unsatisfactory result. All these operations were before 1954 when Logan introduced the technique of transventricular dilatation, which has proved so valuable with difficult valves (Logan, 1959).

Deterioration after a Good Result. The proportion of patients with good results fell from 85 in the first to 66 per cent in the fifth year of follow-up-a steady deterioration rate of 5 per cent a year (Fig. 1). The more rapid deterioration rate in the sixth and seventh years is based only on the earlier cases from the developmental phase of mitral valvotomy; this trend will not necessarily be borne out by further follow-up of the whole 200 (see addendum).

Fig. 2 shows the proportion of patients in each grade of disability at each year of the follow-up. It shows that deterioration among those with good results initially has occurred predominantly in those who were still left with some disability. Those completely relieved of disability, grade 0 , have shown very little deterioration so far; these patients also had more improvement in

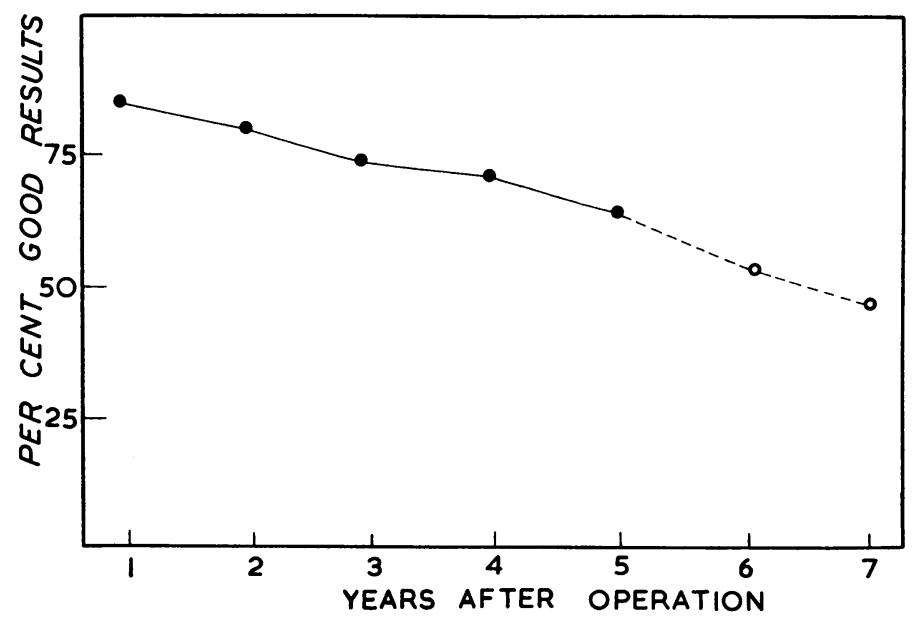

FIG. 1.-The proportion of patients, at each year of the follow-up, showing two or more grades of improvement as compared with their status before operation. Figures for the first five years are expressed as the percentage of 200 patients surviving operation. The interrupted line in the sixth and seventh years indicates that these figures are based on a smaller number of cases (see Table I). 


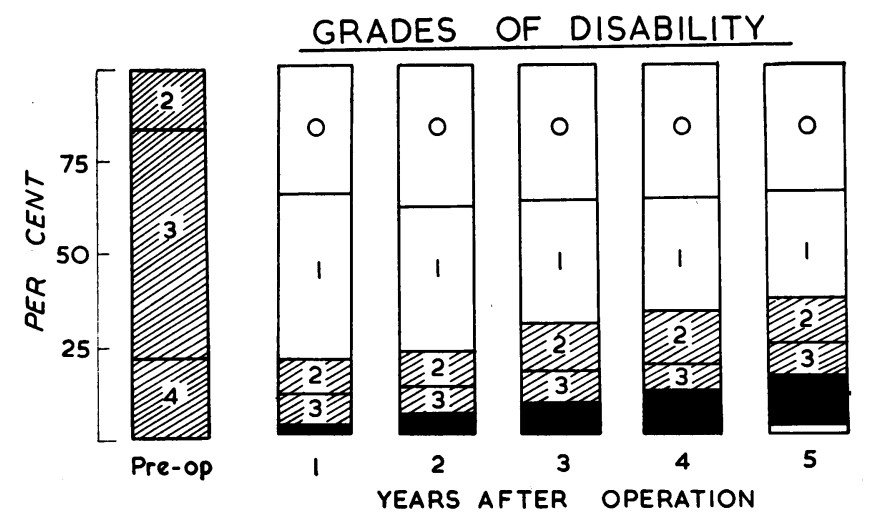

FIG. 2.-The status of 200 patients at each year of the follow-up, expressed as the percentage, showing various grades of disability. The proportion with Grade 4 disability in the follow-up has never been more than 1.5 per cent at any one time, too small to show in the figure.

radiological, electrocardiographic, and physical signs, and were more often instances of pure mitral stenosis, with less evidence of generalized rheumatic heart disease than those who, though good operative results, remained somewhat disabled.

The proportion of patients with grade 2 and 3 disability has not increased greatly, the number slipping into these grades from grade 1 being almost matched by others slipping from grades 2 and 3 into grade 4 and dying. The mortality rate has been about 2.5 per cent each year.

The proportion of patients with grade 4 disability has never been more than 1.5 per cent at any one time in the follow-up, too small to be shown graphically in Fig. 2, although 22 per cent were in this grade of total incapacity before operation. These patients have had more active supervision and medical treatment than before operation, but it is interesting that even in the face of serious deterioration, they have rarely reverted to the invalidism that was conventional in the past. Mitral valvotomy has given them a new lease of life, even if a limited one in many cases; some patients have remained active until shortly before they died.

\section{Causes of Deterioration}

There are three reasons why deterioration may occur after valvotomy. First, the operation may be inadequate and some degree of stenosis remains. Secondly, the valve may restenose. Thirdly, factors inherent in rheumatic heart disease or general factors affecting the circulation may be responsible. The follow-up of the 200 patients will be considered under these three headings.

\section{Results of Good and Inadequate Operations Compared}

The technical results achieved at valvotomy were independently assessed from the surgeon's report made at the time and, like the clinical results, were graded from 4 or excellent to 1 or poor. A grade 4 result corresponds to a division of both commissures, leaving a full opening and mobile valve; a grade 3 result to full opening of one commissure; a grade 2 result a widening of the mitral orifice without full opening of either commissure; and grade 1 to at most a widening of the stenosed valve but not beyond the area of critical tendon insertion (Brock, 1952). Left atrial pressure records at operation were taken into account in this assessment, as was the production of mitral regurgitation; one grade was detracted from the result if significant regurgitation was left.

The surgeon's report correlated with the initial clinical result, and has done so with the long-term follow-up, as shown in Table II. Of 81 patients with a complete valvotomy without significant regurgitation, all had good initial results, and deterioration has occurred in only 9 during the followup. Of the 139 patients where at least one commissure was opened (grades 3 and 4), 112 have maintained good results so far. On the other hand, of the 61 patients in whom only a dilatation 
TABLE II

Operative Result Correlated with Follow-up

\begin{tabular}{|c|c|c|c|c|c|}
\hline \multicolumn{2}{|l|}{ Clinical result } & \multicolumn{4}{|c|}{ Operative result } \\
\hline & & 4 & 3 & 2 & 1 \\
\hline $\begin{array}{l}\text { Good }(119) \\
\text { Deteriorated (51). . } \\
\text { Poor }(30) \ldots\end{array}$ & $\begin{array}{l}\ldots \\
\cdots \\
.\end{array}$ & $\begin{array}{r}72 \\
9 \\
0\end{array}$ & $\begin{array}{r}40 \\
15 \\
3\end{array}$ & $\begin{array}{r}6 \\
21 \\
11\end{array}$ & $\begin{array}{r}1 \\
6 \\
16\end{array}$ \\
\hline Total & . & 81 & 58 & 38 & 23 \\
\hline
\end{tabular}

was achieved, 27 had poor results initially, and 27 of the 34 with good results initially have subsequently deteriorated.

The clinical assessment of a good result after valvotomy was associated with a fall in pulmonary arterial pressure in those who had catheterization after operation, usually at the end of one year. These figures, in 71 patients before, and 47 patients after operation, are shown in Fig. 3. Every patient with a good clinical result who maintained improvement had a satisfactory fall; but those who have deteriorated after initially good results had an almost equally good fall in pulmonary arterial pressure. There was, moreover, little tendency for the pressure to rise again in those who had later catheterization after deterioration had occurred, all three years or more after operation. Fig. 4 shows the same tendency in the 50 catheterizations before and in the 42 after operation where the pulmonary vascular resistance could be calculated. Clearly a falsely optimistic view of the results of operation could be obtained from the pulmonary arterial pressure or pulmonary vascular resistance alone, particularly when this is associated with subjective and functional improvement in the patient.

More reliable evidence is the pulmonary wedge pressure and calculated mitral valve area. In Fig. 5 catheterization before operation in 55 and after it in 39 patients shows that in those where good results have been maintained, the average fall in wedge pressure was considerably better than in those who have deteriorated following initially good results. Later catheterizations in patients deteriorating also showed higher wedge pressures. Similar findings are shown in Fig. 6 where mitral valve area is calculated from right heart catheterization in 53 patients before and 44 after operation. Patients with maintained good results had an increase in mitral valve area to an average of 1.9 sq. cm., only two remaining in the range of critical mitral stenosis. Patients who later deteriorated after initially good results had much less improvement in mitral valve area.

The importance of a technically successful valvotomy in the long-term clinical result is confirmed by these hæmodynamic studies. It would appear that an incomplete mitral valvotomy may lower the pulmonary vascular resistance, with resultant functional improvement enough to give a falsely optimistic view of the operative result. The actual effect on the mitral stenosis may be slight and in those patients future deterioration is inevitable. On the other hand, the functional improvement resulting from a complete valvotomy was associated with improved clinical signs, and with substantial improvement in mitral valve area as well as pulmonary artery pressure; in these patients there has not been a high rate of deterioration.

\section{Restenosis of THE VALVE}

Stenosis of the mitral valve is an inherent part of the pathological process in rheumatic heart disease, so that restenosis after mitral valvotomy may logically be anticipated as a cause of deterioration. It is readily invoked to explain disappointment after operation, often in a period of time much shorter than the development of the original stenosis and not in keeping with the natural history of the disease.

Restenosis after operation is difficult to assess, and our experience in the 200 patients followed 


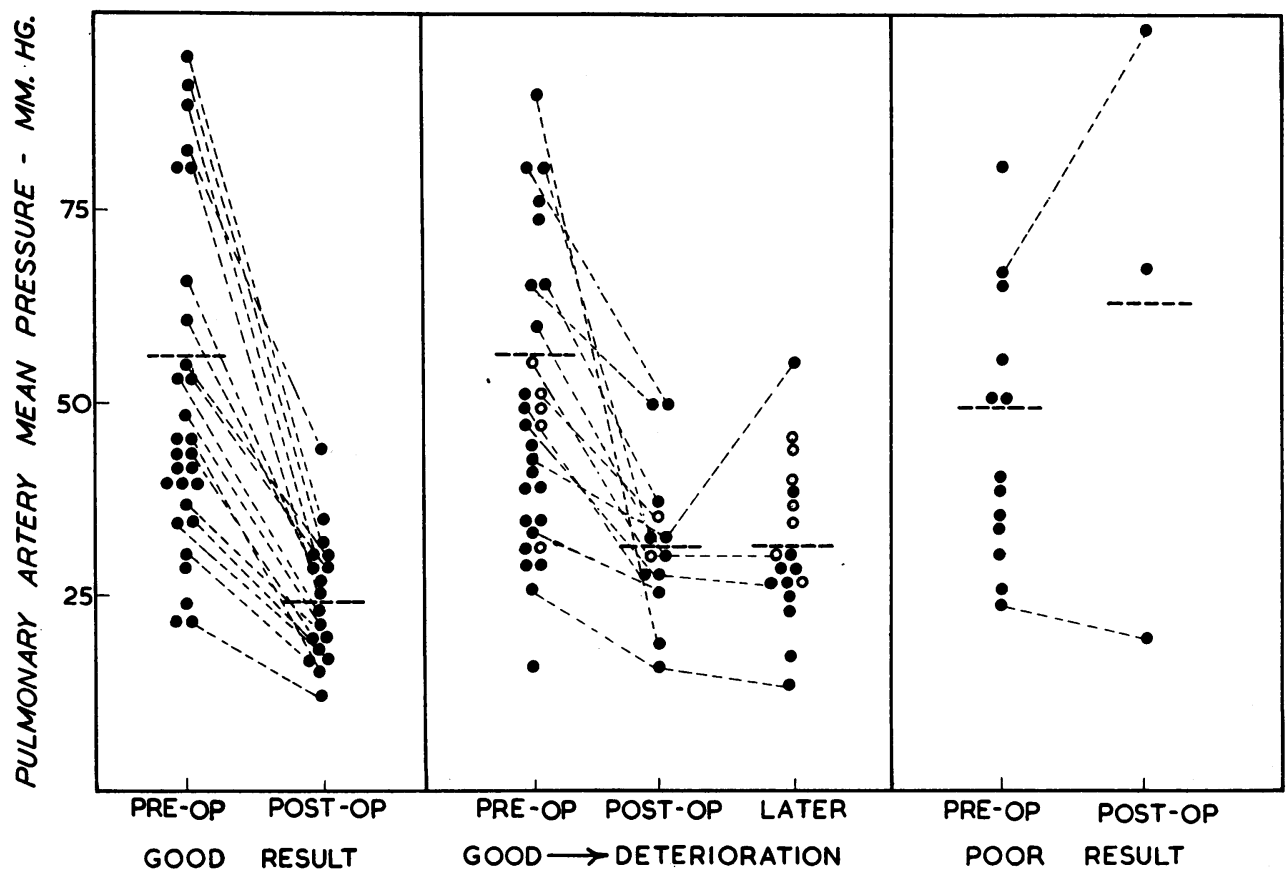

FIG. 3.-Pulmonary arterial mean pressure, in $\mathrm{mm}$. $\mathrm{Hg}$ referred to mid-thoracic level, in 71 patients before and in 47 patients after operation, grouped according to the clinical result five or more years after operation. Serial figures in the same patient are connected by dotted lines. Those deteriorating had nearly as good improvement at first as those maintaining good results, and showed little tendency to develop recurrent pulmonary hypertension later. Open circles in Fig. 35 , and 6 indicate patients with restenosis.

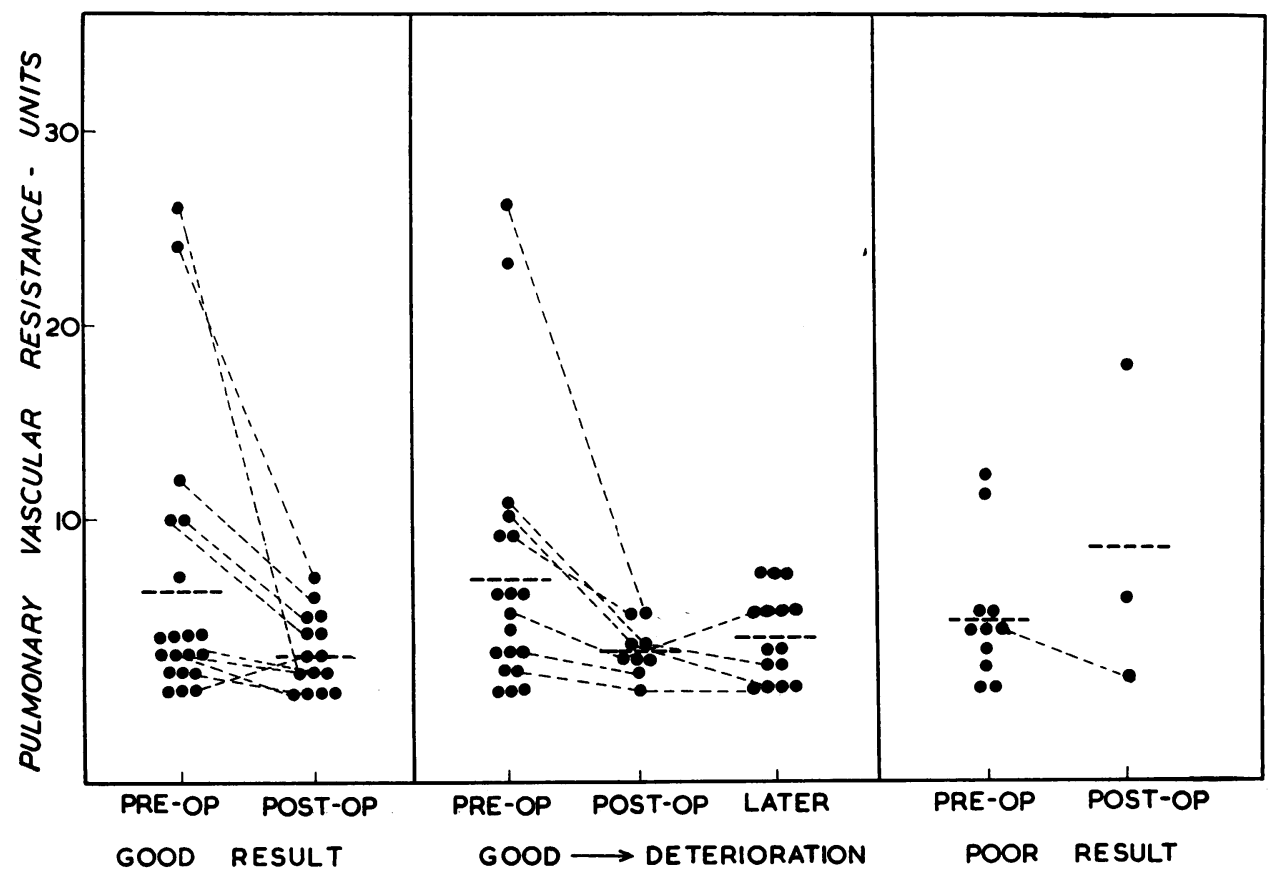

FIG. 4.-Pulmonary vascular resistance, in units (the difference between pulmonary arterial and pulmonary wedge pressures in $\mathrm{mm}$. $\mathrm{Hg}$ divided by the cardiac output in $1 . / \mathrm{min}$.) in 50 patients before and in 42 after operation, grouped according to the clinical result five or more years after operation. This shows that falls in pulmonary artery pressure result from changes in the lungs, not merely from improvement in the mitral obstruction. 


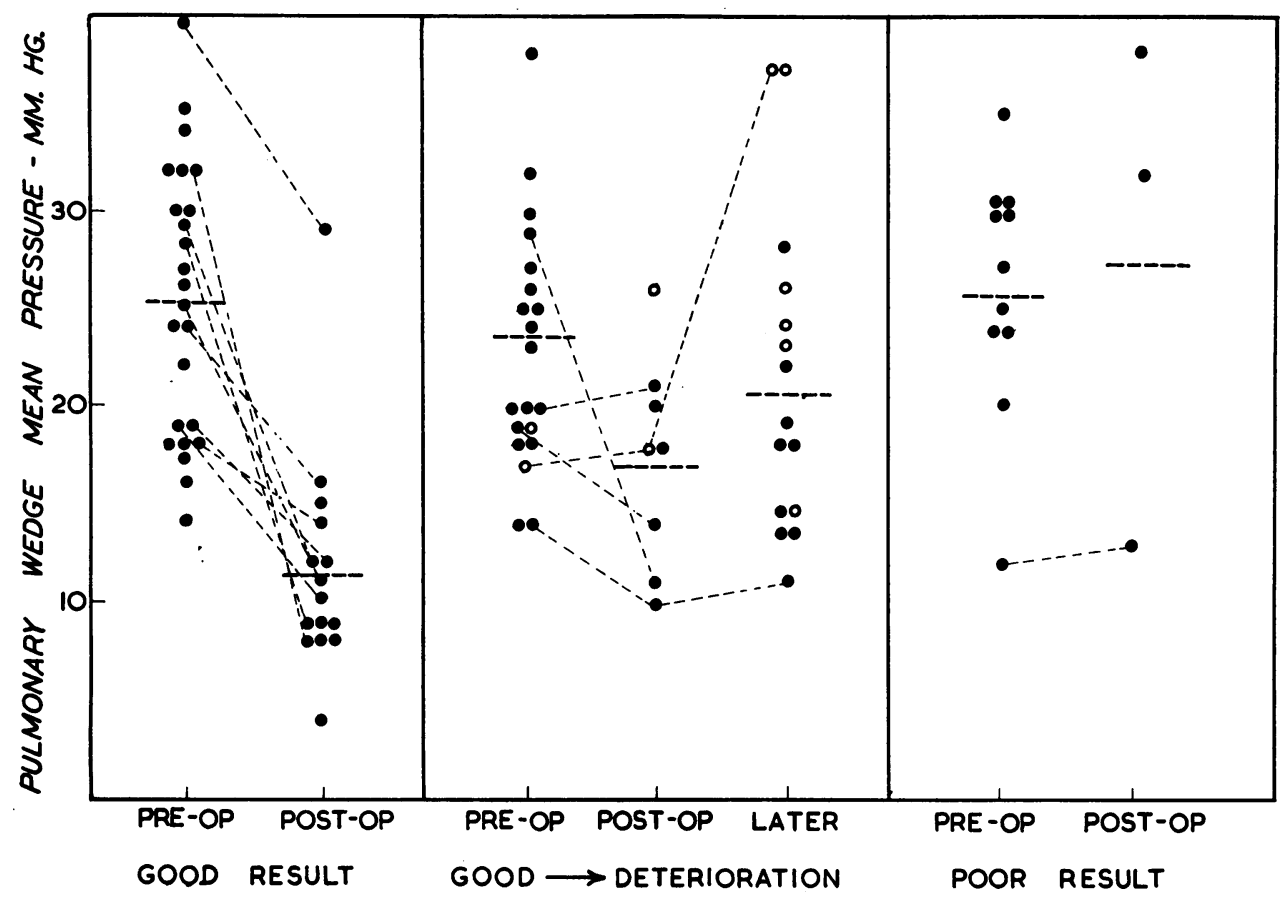

FIG. 5.-Pulmonary wedge pressure, in $\mathrm{mm}$. $\mathrm{Hg}$, referred to mid-thoracic level, in 55 patients before and in 39 after operation, grouped according to the clinical result five or more years after operation. Interrupted lines connect serial observations in the same patient. Those who have maintained their good result showed more improvement than those who have deteriorated, although the initial clinical results were good in both groups.

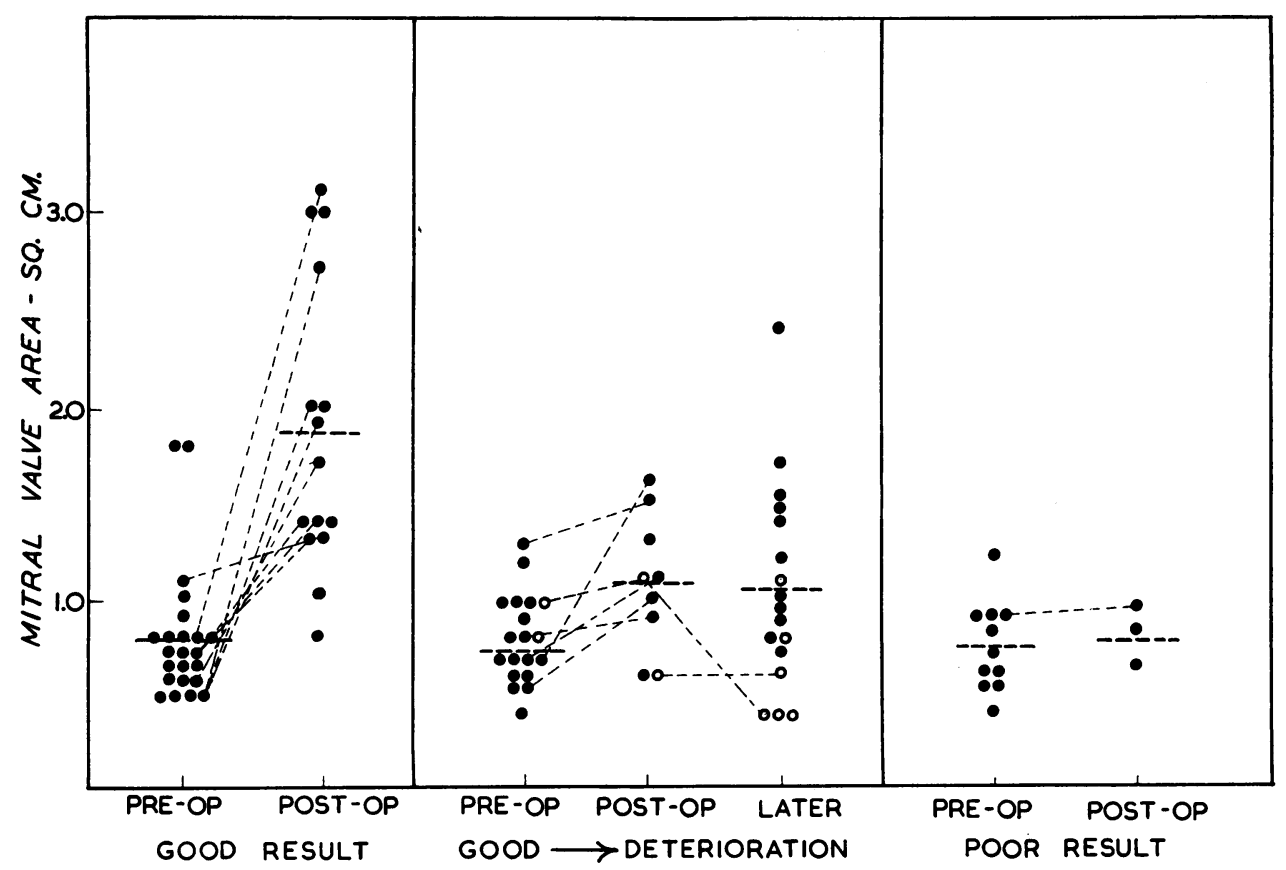

FIG. 6.-Mitral valve area, calculated from right heart catheterization data by the Gorlin formula, in 53 patients before and in 44 after operation. The patients are grouped according to the clinical result five or more years after operation. 
up is that it is not common. In 30 patients with poor results there was no clear evidence of restenosis, either at autopsy or at re-operation, in any patient; in 3 of them some restenosis may have occurred in valves that were only dilated at operation, but this was not proved. Of 51 patients with good initial results but with subsequent deterioration, we considered that 10 showed restenosis, one at autopsy and nine at a second operation. Commissures previously split were found by the same surgeon to have resealed, and a significantly greater degree of stenosis was found than was left at the conclusion of the original operation. In five other patients deteriorating, restenosis may have occurred, but we are not certain, and in none of these was restenosis thought to be the major cause of deterioration. Thus, in our series of 200 patients, there are only 10 proven and 8 possible examples of restenosis.

The details of the 10 patients where restenosis had occurred are shown in Table III. In no patient was a full valvotomy with opening of both commissures and a mobile valve achieved (grade 4 result). In four, one commissure was opened (grade 3), and in the remaining six only a dilatation of the valve (grade 2) was made. In none of the 10 did the physical signs suggest that the stenosis was more than partially relieved.

TABLE III

Details of Patients With Restenosis

\begin{tabular}{|c|c|c|c|c|c|}
\hline & $\begin{array}{l}\text { Age at op. } \\
\text { and sex }\end{array}$ & $\begin{array}{l}\text { Operative } \\
\text { result }\end{array}$ & $\begin{array}{l}\text { Year when } \\
\text { deterioration started }\end{array}$ & $\begin{array}{l}\text { Year of } \\
\text { re-operation }\end{array}$ & Other factors present \\
\hline $\begin{array}{l}1 \\
2\end{array}$ & $\begin{array}{l}26 \mathrm{M} \\
30 \mathrm{~F}\end{array}$ & $\begin{array}{l}2 \\
3\end{array}$ & $\begin{array}{l}3 \\
3\end{array}$ & $\begin{array}{l}8 \\
7 \text { (P.M.) }\end{array}$ & $\begin{array}{l}\text { Tricuspid disease } \\
\text { Pregnancy. Aortic and tricuspid } \\
\text { disease }\end{array}$ \\
\hline 3 & $27 \mathrm{~F}$ & 3 & 7 & 8 & $\begin{array}{l}\text { Bronchitis independent of heart } \\
\text { disease }\end{array}$ \\
\hline $\begin{array}{r}4 \\
5 \\
6 \\
7 \\
8 \\
9 \\
10\end{array}$ & $\begin{array}{ll}35 & \mathrm{M} \\
23 & \mathrm{~F} \\
26 & \mathrm{~F} \\
36 & \mathrm{~F} \\
37 & \mathrm{~F} \\
34 & \mathrm{~F} \\
39 & \mathrm{~F}\end{array}$ & $\begin{array}{l}2 \\
3 \\
2 \\
2 \\
3 \\
2 \\
2\end{array}$ & $\begin{array}{l}5 \\
4 \\
5 \\
4 \\
3 \\
3 \\
3\end{array}$ & $\begin{array}{l}6 \\
6 \\
7 \\
5 \\
5 \\
6 \\
9\end{array}$ & $\begin{array}{l}\text { Bronchitis and asthma } \\
\text { Aortic disease } \\
\text { Aortic disease } \\
\text { Triscuspid disease } \\
\end{array}$ \\
\hline
\end{tabular}

Likewise, none of the patients with restenosis were shown by serial catheterization to have had a satisfactory increase in mitral valve area following the original operation. On the contrary, they were among the patients showing little improvement in pulmonary wedge pressure despite considerable falls in pulmonary arterial pressure and pulmonary vascular resistance.

We find therefore that in our series when restenosis occurred it was on a valve that was not fully opened and mobile, and we would prefer to use the term "partial restenosis" for this occurrence. We have not yet seen restenosis in a valve with a full valvotomy (grade 4), nor in any patient in whom the physical signs or postoperative catheterization indicated satisfactory relief of mitral stenosis, and we would reserve the term "true restenosis" for this.

\section{Other Factors that may CaUSe Deterioration}

Mitral Regurgitation. The assessment of mitral regurgitation after operation was made not only on the surgeons' report but on the physical signs, for these, including electrocardiographic evidence, have shown that significant regurgitation is not always recognized immediately after valvotomy. Patients with mild regurgitation have shown no greater deterioration than those with wholly competent valves (Table IV), for more than two-thirds have maintained a good result. Those with significant regurgitation, however, whether surgically produced or pre-existing, have fared less well, for 16 of 43 had a poor result and 15 have deteriorated after an initial good result: only 12 still maintain good results and 9 of these had a full opening of both commissures, illustrating that mitral 
TABLE IV

Mitral Regurgitation CORRelated With Follow-up

\begin{tabular}{|c|c|c|c|c|c|}
\hline \multirow{2}{*}{\multicolumn{3}{|c|}{ Clinical result }} & \multicolumn{3}{|c|}{ Mitral regurgitation after operation } \\
\hline & & & Significant & Mild & None \\
\hline $\begin{array}{l}\text { Good }(119) \\
\text { Deteriorated (51) .. } \\
\text { Poor }(30) \ldots\end{array}$ & $\begin{array}{l}\cdots \\
\cdots \\
\cdots\end{array}$ & $\begin{array}{l}\ldots \\
\cdots \\
\cdots\end{array}$ & $\begin{array}{l}12 \\
15 \\
16\end{array}$ & $\begin{array}{r}28 \\
6 \\
6\end{array}$ & $\begin{array}{r}79 \\
30 \\
8\end{array}$ \\
\hline Total (200) & $\ldots$ & $\ldots$ & 43 & 40 & 117 \\
\hline
\end{tabular}

regurgitation alone is often well tolerated for a long time. Of 19 patients left with residual stenosis as well as significant regurgitation, only 3 still maintain a good result, which stresses the unfavourable nature of this combined lesion.

There is a close relationship between calcification of the valve and regurgitation. Fifty patients had calcified valves. Of 23 with moderate or severe calcification, 18 had regurgitation after operation; and of 27 with mild calcification 13 had regurgitation of some degree. Partial incisions in the commissures of calcified immobile valves rarely relieve the stenosis satisfactorily and the creation of a full opening may increase the regurgitation severely. Often the surgeon must be content with a compromise between stenosis and regurgitation in such a valve and the clinical result is usually disappointing, immediately or eventually.

Atrial Fibrillation. Table $\mathrm{V}$ shows the number of patients in normal rhythm and atrial fibrillation at various stages of the follow-up. Normal rhythm before operation was associated with rather more initial good results $(90 \%)$ than was atrial fibrillation $(73 \%)$. This was partly explained on the basis of age difference, the older patients having a higher incidence of fibrillation. However, deterioration has occurred more often among those originally showing sinus rhythm, so that by the end of five years follow-up, there was no difference between the two groups.

Fifty-three patients developed atrial fibrillation in the immediate postoperative period, or 45 per cent of those in sinus rhythm. This fibrillation was temporary in 35, reverting either spontaneously or with quinidine, and the long-term results in these have been no different from those in the patient who did not fibrillate. Of the 18 remaining in fibrillation, however, only 7 maintain a good result to date.

An additional 26 patients have developed permanent fibrillation during the follow-up period. Often this was preceded by paroxysmal fibrillation, sometimes for several years. In 5 cases the

TABLE V

Atrial Fibrillation correlated with Follow-up

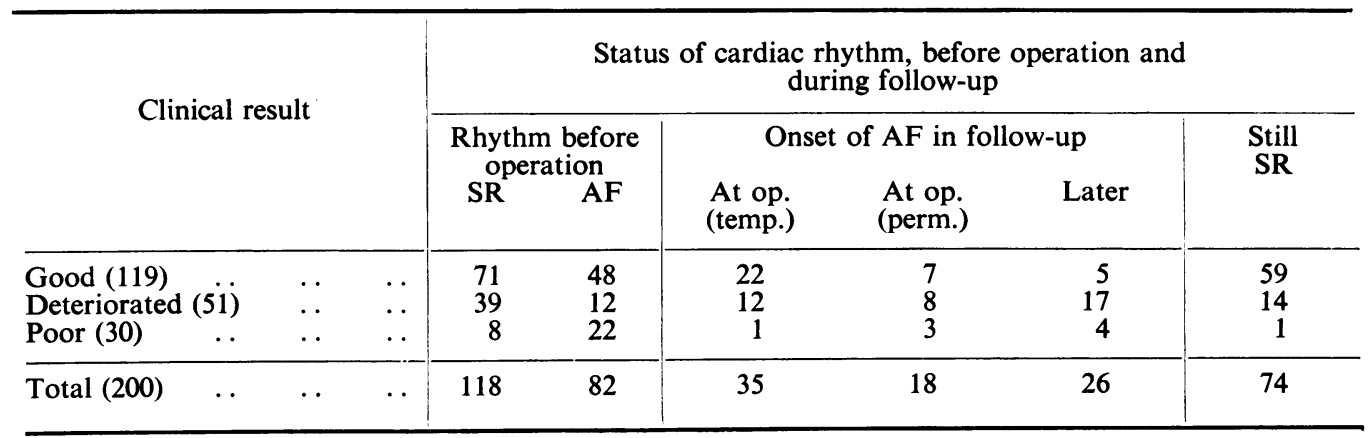


onset of permanent fibrillation was well tolerated, only noticed at their routine yearly examination, and not associated with any deterioration in clinical status, even when they were not digitalized.

Most of the patients developing permanent fibrillation in the follow-up period were, however, in the group deteriorating after a good initial result. Usually the onset of the arrhythmia coincided with the clinical deterioration, which persisted in spite of digitalization and medical treatment. The close association between deterioration and fibrillation is shown in Fig. 7. The rate at which patients in the group who deteriorated have developed fibrillation suggests that few of them will remain in normal rhythm much longer, and we think that fibrillation is more the result than the cause of deterioration. Patients with more severe mitral disease fibrillate more readily and their poor toleration of this brings to light the fact that the result is not as satisfactory as it seemed.

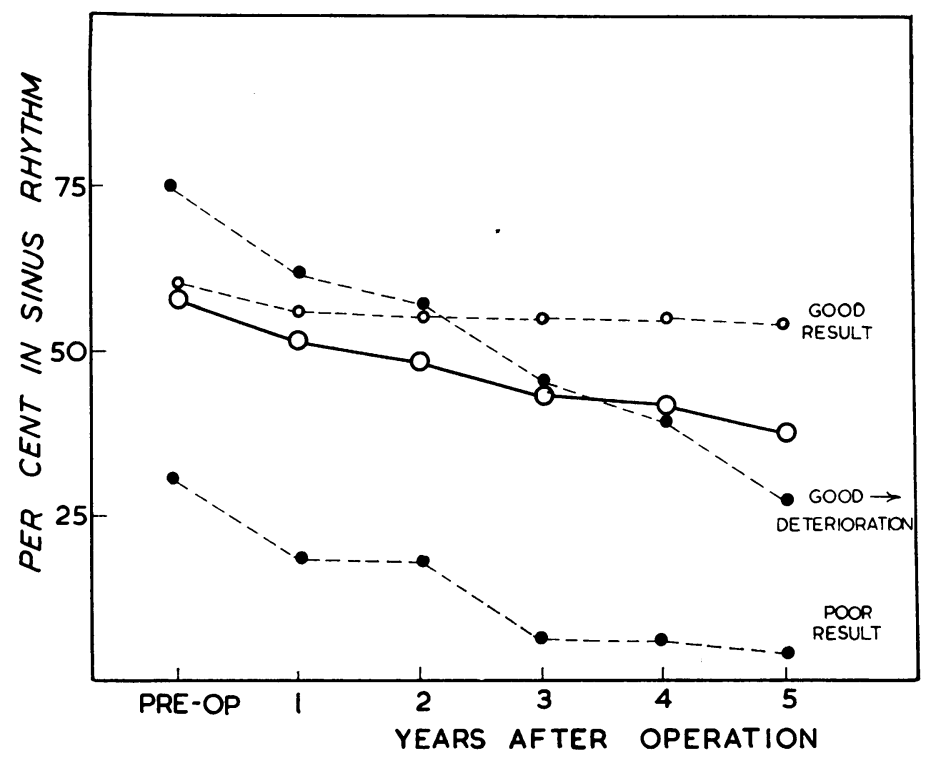

FIG. 7.-The proportion of patients in normal rhythm at each year of the follow-up, showing the rate at which atrial fibrillation has developed. The curve is shown for the group as a whole, and also for the good, deteriorated, and poor results as assessed five or more years after operation. Those with poor results or deterioration after initially good results have a much higher rate of development of fibrillation than those maintaining good results.

Aortic and Tricuspid Disease. No patient with dominant aortic disease was included in this series. Excluding 18 where the evidence of regurgitation was only a grade 1 murmur, there were 27 who had aortic disease of some significance. In 10 patients the signs were of stenosis without regurgitation but in only one was a pressure gradient of $40 \mathrm{~mm}$. measured at operation considered high enough to warrant aortic as well as mitral valvotomy. Functional tricuspid regurgitation was common before mitral valvotomy but organic tricuspid disease was diagnosed in 18, and combined aortic and tricuspid disease in a further 20 patients.

The follow-up results in these 65 with aortic and tricuspid disease are shown in Table VI and contrasted with the 135 with mitral disease alone. The proportion of good results maintained throughout the follow-up $(40 \%)$ is smaller and deterioration from good results greater $(37 \%)$ in those with associated valve disease, compared with 69 per cent of good results and 20 per cent deteriorations in those without. Lesions of the other valves, though no contraindication to relief of severe mitral stenosis, are evidence of more extensive rheumatic heart disease, which must influence prognosis quite apart from the result of mitral valvotomy. 
TABLE VI

Associated Aortic and Tricuspid Valve Disease correlated with Follow-up

\begin{tabular}{lll|cc|c|c|c}
\hline & & Number & Good & Deteriorated & Poor \\
\hline Aortic valve disease $\ldots$ & $\ldots$ & $\ldots$ & $\ldots$ & 27 & 12 & 8 & 7 \\
\hline Tricuspid valve disease &. & $\ldots$ & $\ldots$ & 18 & 5 & 8 & 5 \\
\hline Aortic and tricuspid disease .. & $\ldots$ & $\ldots$ & 20 & 9 & 8 & 3 \\
\hline Total with associated valve disease $\ldots$ & $\ldots$ & 65 & 26 & 24 & 15 \\
\hline Total without associated valve disease & $\ldots$ & 135 & 93 & 27 & 15 \\
\hline
\end{tabular}

We have found occasionally that the signs of aortic and tricuspid disease have become more obvious after successful mitral valvotomy, presumably due to an improved cardiac output (Mounsey, 1959). In others, the signs of disease have progressively increased during the follow-up. This we noticed particularly with tricuspid disease, as is shown in the great increase in the size of the right atrium in Fig. 8. This was not associated with any clinical evidence of rheumatic activity or congestive failure but is convincing evidence that rheumatic heart disease does progress even after a successful mitral valvotomy. Thus, we may see a higher incidence of tricuspid disease in patients who are given a longer span of life through relief of their more serious mitral stenosis.

Chronic Pulmonary Disease. Patients with mitral valve disease are commonly subject to two sorts of chronic pulmonary disease, the pulmonary vascular disease that leads to pulmonary hypertension, and the chronic bronchitis and emphysema that may co-exist as a separate condition. In the early development of mitral valvotomy it was feared that irreversible changes in the lungs might prevent good results from operation in many cases, but this has not been borne out by experience. Severe pulmonary hypertension before operation has not affected adversely the initial or long-term results (Fig. 3). Moreover, recatheterization later in those who have deteriorated has shown little tendency for the vascular resistance in the lungs to rise again. That some damage may remain from lung disease after successful valvotomy is suggested by the electrocardiogram, for evidence of right ventricular hypertrophy does not always completely disappear and Torres et al. (1959) have shown that the regression of signs occurred more readily when the history of symptoms was short.

Chronic bronchitis and emphysema have been, however, a significant factor in the follow-up. Because the symptoms of this closely resemble those often resulting purely from mitral stenosis, it is difficult to assess accurately. Many patients, however, who may be confined to home or bed for a short period during the winter months with chronic bronchitis, distinguish this from their pulmonary symptoms before mitral valvotomy particularly by the absence of orthopnœa. We felt that 9 (or 18 per cent) of the 51 patients who have deteriorated had significant pulmonary disease, and that in 4 this was a dominant factor in the deterioration. Severe emphysema has developed during the follow-up in several, illustrated in Fig. 9 by serial X-rays in one patient who has shown an apparent diminution in heart size as the lungs have become progressively over-inflated.

Chronic bronchitis does not necessarily prevent a good result from mitral valvotomy, however, as it is present in $16(13 \%)$ of the patients who still maintain a good result.

Pregnancy. Pregnancy is often a critical event in the lives of patients with mitral stenosis, as a time when the condition is discovered or when serious symptoms are first manifested. Valvotomy in 4 of the 200 patients was done during pregnancy as an emergency measure, in three because of pulmonary œdema, and all were successfully delivered at term. It is still a critical event in many patients who have had mitral valvotomy. In all, 21 patients have become pregnant during the follow-up period, and four of them had a second child. Eleven of these were in the group maintaining good results, and their pregnancies were accomplished without serious difficulty, including 


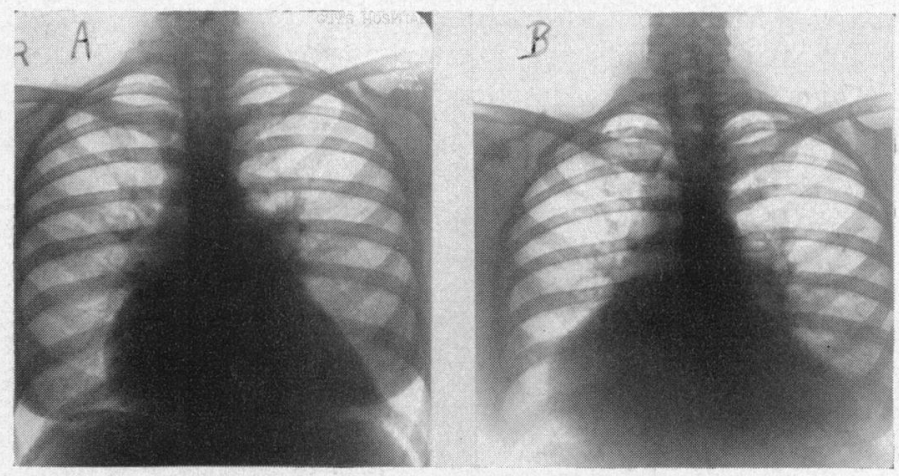

FIG. 8.-Radiographs of woman aged 30, with mitral stenosis and tricuspid regurgitation (T.R.), and with grade 3 disability. (A) May 1951 , one day before a grade 3 valvotomy. Good result maintained with no clinical deterioration in follow-up. (B) May 1958. Showing increase in right atrium. Signs of T.R. have progressed steadily but without failure. Active life with no symptoms except on heavy exertion (disability grade 1 ).
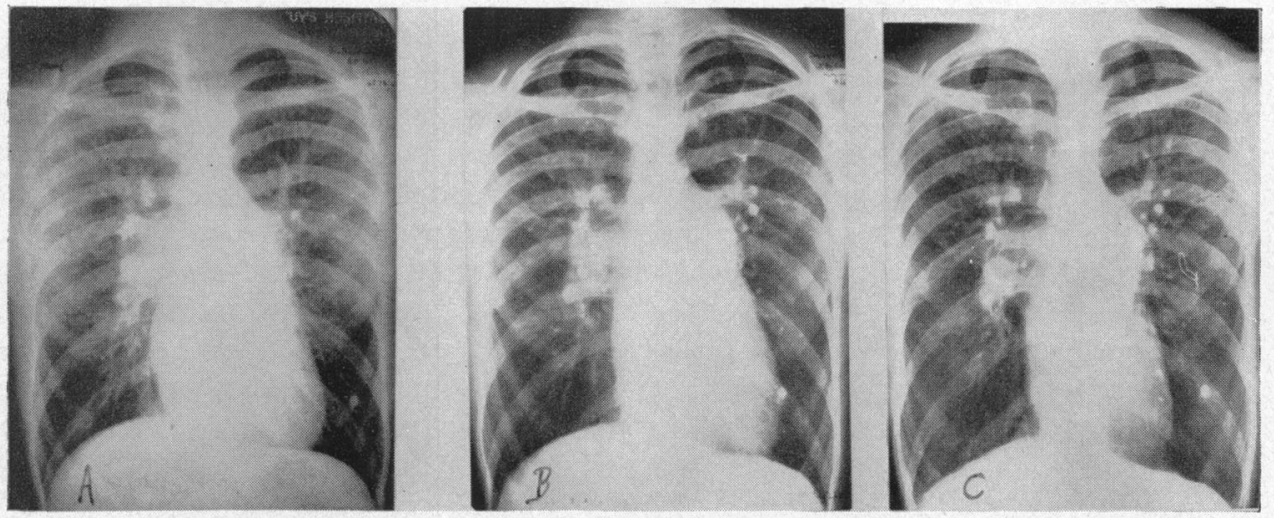

FIG. 9.-Radiographs of a man aged 26 at the time of valvotomy in 1950 . (A) Three years before valvotomy. Severe pulmonary venous congestion. Catheter a year later showed mean P.A.P. of $80 \mathrm{~mm}$. $\mathrm{Hg}$, cardiac index 2.41 ./sq. m./sec., $\mathrm{O}_{2}$ saturation of mixed venous blood 60 per cent. (B) The day before valvotomy. P.V.C. minimal and a pulmonary hypertensive picture. Catheter one month before showed mean P.A.P. of $100 \mathrm{~mm}$. $\mathrm{Hg}$, cardiac index $2 \cdot 7, \mathrm{O}_{2}$ saturation of mixed venous blood 45 per cent. (C) Six years after valvotomy. P.A. still large but increase of X-ray appearances of emphysema. Catheter one year before had showed P.A. mean pressure of 32 , cardiac index $1 \cdot 8, \mathrm{O}_{2}$ saturation of mixed venous blood 58 per cent, and calculated valve area $1.52 \mathrm{sq} . \mathrm{cm}$.

a first one at the age of 39 , seven years after valvotomy. Two patients, however, with poor results deteriorated further after pregnancy. The other 8 were among the 51 who deteriorated from good results and in 6 of these recurrence of cardiac symptoms during pregnancy was the first indication of deterioration: all were good rather than excellent results and in none of them had valvotomy been complete. Pregnancy was a rigorous test of the cardiac reserve in these patients, as it is in those who have not had an operation.

Bacterial Endocarditis. Bacterial endocarditis did not develop as an early postoperative complication in any of these patients, but in two it developed later in the follow-up. Both of these were deteriorating after an initial result that was good, and subacute bacterial endocarditis, found at autopsy, was thought to be the principal cause of death in one. 
Arterial Embolism. Arterial embolism has occurred in 8 patients since operation, an incidence of about 0.5 per cent each year. In only one, with a poor operative result, did the embolism cause serious disablement. Five of these episodes were in patients who deteriorated from good results, though in three embolism preceded clinical deterioration by two years or more. Two have maintained good results for three and four years after embolism. Of the 8 patients 4 were in sinus rhythm at the time of their post-operative embolism, two of these fibrillated two and three years after the embolism, and two still remain in sinus rhythm.

Hypertension. Systemic hypertension has developed since operation in 9 of the patients in the group that deteriorated. It was the main cause of deterioration and subsequent death in 1 of these and an important factor in 2 others who died. In the remaining 6, and in 14 who still remain good results it has so far seemed of little importance, thought it must add to the work of the heart and may well be a cause of deterioration later.

Rheumatic Activity. Of 111 atrial biopsies critically examined for evidence of rheumatic activity, this was strongly suggestive in 24 and possible in 20 per cent. There was no correlation of these findings with the results of valvotomy, or with clinical evidence of rheumatic activity after operation or in the follow-up. Recurrence of the post-pericardectomy syndrome and the tendency for patients who were disappointed in the operative results or in life generally to complain of "rheumatism"- a complaint not uncommon in patients without rheumatic heart disease-made the diagnosis of continued rheumatic activity difficult. Only 2 patients had frank rheumatic fever and both were among the 51 who deteriorated from good results; rheumatic activity was also strongly suspected in 6 others of these but in none of the 8 was it the sole cause of deterioration. In those who maintained good results only 2 were suspected of rheumatic activity but our confessed inability to diagnose this does not mean that it is not a factor in the progression of rheumatic heart disease after mitral valvotomy.

The follow-up in relation to age incidence shows that deterioration from good results tended to occur more in the younger patients. The initial good results were 95 per cent in the age group 20-29 compared with 82 per cent in the 40-49 age group, while at the end of five years the good results were 58 and 70 per cent respectively. In fact deterioration occurred in 38 per cent of those with initially good results in the 20-29 group but in only 15 per cent of those in the 40-49 group, while the 30-39 group was intermediate. That a higher percentage of initially good results occurred in younger patients than in older may be due to a greater capacity to take advantage of the operative result; but that this is not so long maintained as in older patients may be due to an increased tendency to active rheumatic heart disease. Ellis et al. (1959) in 361 patients followed up for five years or more, found an incidence of 19 per cent with rheumatic fever in those who deteriorated after substantial improvement compared with 1.5 per cent in those who maintained improvement. Although our findings do not produce such strong evidence of rheumatic carditis as a cause of deterioration after mitral valvotomy we consider it is a factor that must operate, but one that is difficult to assess.

The Myocardial Factor. The most difficult factor to assess in these patients is the part played by the myocardium. Clinical criteria are not specific even when supplemented by hæmodynamic and pathological study. Nevertheless we think that in some patients with signs of mitral stenosis the mechanical valve defect is trivial and myocardial failure is dominant. Of the 51 patients deteriorating after initially good results, 8 showed no good explanation in the factors already discussed, and their increasing disability has seemed to us myocardial. This was not entirely a diagnosis of exclusion, for in 6 catheterization did not indicate significant stenosis, and in the other 2 the physical signs did not even warrant catheterization. Five are over 40, all are fibrillating, all are without or almost without pulmonary hypertension, and 4 have a notably episodic history of increase of symptoms or heart failure. It would seem reasonable to think that a myocardial factor has contributed to deterioration in other patients and may well be present in those who still maintain good results.

When a dominant myocardial factor is recognized, operation or re-operation is best avoided. 
Cardiac catheterization may be of real value in demonstrating that the mitral valve area is not critically narrowed.

\section{Discussion}

Few statistical reports have been published of the results of mitral valvotomy five or more years after operation. Ellis et al. (1959) found in 361 patients followed for five years or more that the initial improvement rate of 79 per cent had fallen to 51 per cent, and 14 per cent had died-figures very similar to ours. Likoff and Uricchio (1958) assessed their first 200 patients five to eight years later, and considered 55 per cent of them still moderately or greatly improved. The rate of deterioration, however, is not clearly evident from their figures, nor is it from those of Glover et al. (1955) who assessed their first 50 cases five or more years after operation and found 20 still markedly improved and 16 improved. In so far as they can be compared, these studies agree in indicating that mitral valvotomy in the years 1948-53 resulted in significant improvement in about 80 per cent of survivors, but that about 5 per cent have since deteriorated each year.

The importance of restenosis of the valve as a cause of deterioration is difficult to assess, both in our experience and in the reported experience of others. This is partly a matter of definition; terms such as recurrence or reconstitution of mitral stenosis may not be used in the same sense as actual restenosis, which should imply that valve leaflets have fused together as they did in the original rheumatic process. Another source of difficulty is that the surgeon may occasionally overestimate the extent of a commissurotomy, subsequent findings being mistakenly interpreted as restenosis.

We considered that 10 of our patients showed partial restenosis, but none true restenosis. Belcher (1958) made a similar distinction in reporting 12 re-operations from a series of 240 and in reviewing the scanty reports about restenosis. He calls deterioration after an inadequate operation false restenosis and deterioration after a good valvotomy true stenosis, but of the four patients so diagnosed only one had a first operation that was "almost complete"; the other 11 would all come under our definition of partial restenosis. Very few of the reported cases of mitral stenosis recurring after operation are accompanied by objective evidence that the original operation really abolished the mitral obstruction. Soulié et al. (1957), in reporting 6 re-operations for recurrent mitral stenosis also thought that the original operation had been incomplete: one of their cases showed a reduction of pulmonary wedge pressure from 26 to $12 \mathrm{~mm}$. $\mathrm{Hg}$ after the first operation, with a later rise to 25 when deterioration occurred, but even this was felt not to have been a complete operation. Patterson and Marshall (1959) found 7 instances of restenosis after 400 operations: two of these had had both commissures completely split, but the deterioration at eight months in one seems too early for restenosis. Again, there is no objective evidence, from physical signs or catheterization, that the stenosis had been abolished originally.

A second operation is reasonable if there is a significant mechanical obstruction at the mitral valve, either from restenosis or an incomplete first operation, that can be relieved surgically. Cardiac catheterization may be needed to demonstrate the obstruction and the previous operative findings will indicate whether a second attempt offers a reasonable chance of success. Twenty of our patients had a second operation. In only 4 of the 30 with poor results was this advised and in 3 the result was again disappointing. Of the 51 patients who deteriorated from good results, 16 had a second operation, 9 with partial restenosis and 7 with incomplete valvotomy: there were two deaths. The first two re-operations were four years ago but in the remaining 12 the follow-up is insufficient to assess the result, although it seems unlikely that the proportion receiving lasting success will be high, for in only one was a complete valvotomy possible at the second operation. Nevertheless 14 of the 18 survivors from a second operation have reason to be grateful for a renewed lease of life, even though this may prove less than they expect.

Although the main object of this paper is to report and assess deterioration after mitral valvotomy it is important to stress that 119 out of 200 patients still have good results and that over half of these have no apparent disability. In spite of a significant incidence of deterioration due to residual or recurrent mitral stenosis we think the follow-up results confirm the long-term value of mitral 
valvotomy and provide some basis for evaluating the need for, and the results of, newer techniques such as surgery of the mitral valve under direct vision.

\section{ConCLuSIONS}

Of 200 consecutive patients surviving mitral valvotomy, 85 per cent had a good or excellent result when assessed one year after operation.

During the first five years of follow-up, 5 per cent per year deteriorated: 82 per cent of those who deteriorated were accounted for wholly or partially by a valvotomy that was technically incomplete.

Restenosis occurred in 10 cases or 1 per cent per year, always in patients with an incomplete valvotomy. No patient with a complete valvotomy has yet deteriorated from restenosis alone.

Significant mitral regurgitation and the onset of atrial fibrillation were factors frequently associated with deterioration. Chronic pulmonary disease, aortic and tricuspid valve disease, pregnancy, bacterial endocarditis, systemic hypertension, and myocardial failure were also significant factors in some patients.

We are indebted to many, but primarily to Sir Russell Brock for his pioneer work in introducing and establishing mitral valvotomy; he operated on the first 48 patients and on a total of 104 out of the 200 followed up. The other surgeons whose patients are included are Mr. Milstein (19), Mr. Starkey (1), Mr. Robert Brain (11), and Mr. Ian Hill, whose parallel but independent follow-up of his 65 patients has been particularly helpful. Dr. Maurice Campbell played a large part in the introduction of mitral valvotomy and was a collaborator in the original report and two succeeding papers; 25 of these patients were his, and his help has been invaluable in the follow-up.

Hæmodynamic studies were started at Guy's by Dr. Edward Holling and to him we are in lasting debt. The investigators who followed and maintained the high standard he set, the medical registrars, the technical staff, and the many physicians and practitioners who supplied information are too numerous to name, but we thank them all for their generous and continued help which has contributed to this paper.

\section{ADDENDUM}

A further year of follow-up just completed shows 63 per cent good results after six years, a fall of only 3 per cent from the fifth year. In the total follow-up period of 6 to 11 years 54 per cent have still good results without deterioration.

\section{REFERENCES}

Baker, C., Brock, R. C., and Campbell, M. (1950). Brit. med. J., 1, 1283.

,,-- (1955). Brit. med. J., 2, 983.

_ _ _ - and Wood, P. (1952). Brit. med. J., 1, 1043.

Belcher, J.' R. (1958). Brit. Heart J., 20, 76.

Brock, R. C. (1952). Brit. Heart J., 14, 489.

Ellis, L. B., Harken, D. E., and Black, H. B. (1959). Circulation, 19, 803.

Glover, R. P., O'Neill, T. J. E., and Janton, O. H. (1955). J. thorac. Surg., 30, 436.

Likoff, W., and Uricchio, J. F. (1958). J. Amer. med. Assoc., 166, 737.

Logan, A. (1959). Personal communication.

Mounsey, J. P. D. (1959). Brit. Heart J., 21, 123.

Patterson, G. C., and Marshall, J. R. (1959). Brit. Heart J., 21, 174.

Soulié, P., Joly, F., Carlotti, J., and Servelle, M. (1957). Amer. Heart J., 54, 695.

Torres, R. V. R., Mackinnon, J., Wade, E. E., and Vickers, C. J. (1959). Brit. Heart J., $21,381$. 